\title{
A PESQUISA ESCOLAR PROPICIANDO A INTEGRAÇÃO DOS ATORES - ALUNOS, EDUCADORES E BIBLIOTECÁRIOS - IRRADIANDO O BENEFÍCIO COLETIVO E A CIDADANIA EM UM AMBIENTE DE APRENDIZAGEM MEDIADO POR COMPUTADOR
}

\author{
Eliane Lourdes da Silva Moro* \\ Lizandra Brasil Estabel $^{* *}$
}

\begin{abstract}
RESUMO: Este artigo aborda sobre o processo da pesquisa escolar compreendido como um novo paradigma no cenário da sala de aula. A pesquisa escolar no papel de integração e interação dos seus atores principais: os alunos, os educadores e os bibliotecários. O uso das Tecnologias de Informação e de Comunicação (TIC's) e o acesso às ferramentas de pesquisa estimulam os usuários a ampliar suas informações, desenvolver a curiosidade e o espírito crítico e reflexivo. Apresenta a biblioteca escolar e a sua importância no processo metodológico da pesquisa, desde as séries iniciais do Ensino Fundamental ao Ensino Médio e o papel ativo dos protagonistas da pesquisa escolar, na construção de um novo paradigma, constituindo uma ação pedagógica digital em um Ambiente de Aprendizagem Mediado por Computador - AAMC.
\end{abstract}

Palavras-Chave: Pesquisa Escolar; Tecnologias de Informação e de Comunicação; Biblioteca Escolar.

\begin{abstract}
This article aims at approaching the process of school research based on a new paradigm in the classroom scenery. School research is here seen as playing an interactive and integrative role with the support of its main actors: the learners, the educators, and the librarians. The use of Information and Communication Technologies ICT and the access to the research tools motivate the users not only to enlarge their information and to develop their curiosity but also to drive them towards a more critical and reflective mind. It also presents the school library and its importance in the methodological process of research, from the initial years in Elementary School to Secondary School, as well as to catalyze the active role of the protagonists of the school research towards the construction of a new knowledge paradigm, constituting a digital pedagogical action when utilizing a Collaborative Environment Mediated by the Computer.
\end{abstract}

Key-words: School Research; Technologies of Information and Communication; School Library.

\section{INTRODUÇÃO}

A pesquisa escolar constitui uma das principais atividades realizadas no processo de ensino e de aprendizagem, desde as séries iniciais do Ensino Fundamental ao Ensino Médio. Apresenta, dentre os princípios básicos auxiliar o aluno a estudar com independência, planejar, conviver e interagir em grupo, aceitar as opiniões dos outros, usar adequadamente a biblioteca, utilizar as fontes de consulta, desenvolver o pensamento crítico e o gosto pela leitura, adquirir autonomia no processo de conhecimento, aprender a trabalhar colaborativa e cooperativamente, entre outros.

Como pesquisa entende-se o procedimento racional e sistemático, com método de pensamento reflexivo que requer um tratamento científico e tem como objetivo buscar respostas aos problemas sugeridos. A pesquisa escolar deveria se caracterizar

\footnotetext{
* Professora do Curso de Biblioteconomia da FABICO/UFRGS, Especialista em Informática na Educação PGIE/UFRGS. E-mail: mmoro@adufrgs.ufrgs.br.

*** Professora do Curso de Biblioteconomia da FABICO/UFRGS, Doutoranda em Informática na Educação PGIE/UFRGS. E-mail: estabel@cpovo.net .
} 
como uma atividade sistematizada, um processo formal, que visa encontrar respostas para questões propostas pelo professor ou pela própria turma. Algumas condições iniciais que permitam aos alunos conhecer e exercitar os procedimentos da metodologia científica são recomendáveis para a realização da pesquisa escolar. É interessante que o professor, ao solicitar a pesquisa escolar, re-lembre aos alunos os procedimentos que podem servir de orientação para o início, o desenvolvimento e a conclusão do trabalho, tais como: o que, de que trata o trabalho, para que será realizado, quanto (dimensão), quando (prazo para entrega), onde o assunto pode ser encontrado e como forma da comunicação do trabalho.

Por outro lado, as fontes que podem ser utilizadas para a realização da pesquisa escolar, podem ser apresentadas no suporte bibliográfico e no suporte eletrônico. É importante também a orientação dos professores e do bibliotecário nas estratégias de busca para localização dos assuntos que os alunos vão desenvolver na realização do trabalho escolar. A Pesquisa Escolar utilizando as Tecnologias de Informação e de Comunicação - TIC's estão presentes no cotidiano da escola. As TIC's disponíveis na biblioteca escolar, na biblioteca pública e em outros locais onde os alunos vão buscar as informações, devem estar adequadas para o nível de escolaridade em que o aluno se encontra.

Torna-se importante que o professor e o bibliotecário oportunizem o acesso às ferramentas de pesquisa estimulando os usuários a ampliar suas informações, desenvolver a curiosidade e o espírito crítico. As estratégias para o melhor uso das tecnologias devem propiciar a interação entre o bibliotecário, os professores e os alunos e estes entre si, criando um ambiente de estímulo e apoio às atividades de ensino e de aprendizagem.

\section{A PESQUISA ESCOLAR NO CENÁRIO DA SALA DE AULA}

O Manifesto da Unesco de Declaração Mundial Sobre Educação para Todos III: Missão e Objetivos da Biblioteca Escolar aponta que a missão da biblioteca escolar é a de estimular o processo do ensino e da aprendizagem. Seus pontos básicos se referem "ao desenvolvimento da informação, da alfabetização, da educação (ensino e aprendizagem) e da cultura", devendo compor os serviços fundamentais da Biblioteca Escolar. Dentre os objetivos que o Manifesto aponta para a biblioteca escolar, podem-se destacar:

Apoiar e fortalecer as metas da educação como parte integrante do currículo escolar;

Estimular a aprendizagem e a prática na habilidade da leitura (alfabetização) relacionada a identificação, seleção, recuperação, uso, aplicação e interpretação da informação, independente do suporte, incluindo a tradição oral;

Proporcionar oportunidade para o desenvolvimento de atividades individuais ou em grupo no uso e criação de dados informacionais, independente do suporte, para o desenvolvimento de conhecimento, imaginação e recreação;

Promover a pesquisa a nível local, nacional e mundial, organizando atividades que desenvolvam a sensibilidade e consciência cultural e social; 
Promover pesquisas e oportunidades de aprendizagem que representam a diversidade de idéias, experiências e opiniões, atendendo as necessidades e condições locais e nacionais;

Facilitar a promoção da educação continuada, individualmente e em grupo;

Garantir um ambiente em que a importância da alfabetização, da capacidade para a leitura e cálculos seja reconhecida;

Enfatizar o conceito de que a liberdade intelectual e o acesso à informação são prérequisitos básicos para o fortalecimento da cidadania e da democracia;

Fornecer instrução e assistência no uso da informação tecnológica e das pesquisas divulgadas nos vários meios de comunicação;

Facilitar a formação de um centro de informação na escola, além da biblioteca e o acesso a informação por meios tecnológicos como, por exemplo, a Internet. (UNESCO, 1998, p.2-3)

Segundo Valente (1999) vive-se hoje em um mundo dominado pela informação e por processos que ocorrem de uma maneira muito rápida e imperceptível. Por isso, é importante que, ao invés do aluno memorizar informação, aprenda a buscar e a usar essa informação da forma que melhor lhe convier. Sendo assim, o computador se torna um excelente auxiliar para os alunos exercitarem "a capacidade de procurar e selecionar informação, resolver problemas e aprender independentemente."

$[\ldots]$. . . a informática deverá assumir duplo papel na escola. Primeiro, deverá ser uma ferramenta de atuação na escola, propiciando a presença virtual de pesquisadores e auxiliando cada um dos profissionais na realização de ações que contribuam para a mudança da escola. Em outros momentos, a Informática poderá ser usada para suportar a realização de uma pedagogia que proporcione a formação dos alunos, possibilitando o desenvolvimento de habilidades que serão fundamentais na sociedade do conhecimento. ( ${ }^{1}$ VALENTE, 1999, p.43 apud FARIA, 2002, p.56).

Na sala de aula, a relação professor e aluno se estrutura nos papéis de "quem ensina" e de "quem apreende", no processo de ensino e de aprendizagem. A pesquisa escolar, na visão do professor, geralmente é utilizada mais como uma atividade escolar para ser avaliada no decorrer da unidade de estudo programada do que uma atividade onde o aluno vai utilizar e complementar os conhecimentos adquiridos. A pesquisa escolar deve ser uma atividade em que os alunos tenham oportunidade de estudo independente, de planejamento de trabalho, de uso de fontes de informação, de

${ }^{1}$ VALENTE, J. A O Computador na Sociedade do Conhecimento. Brasília : MEC- PROINFO, 1999.

(Coleção Informática para Mudança na Educação). Apud FARIA, E. V. de. Anais ... Florianópolis : SBC, 2002. P.55-64 
desenvolver o pensamento crítico, de adquirir autonomia no processo de conhecimento, de aprender a trabalhar com seus colegas colaborando e contribuindo com o grupo, de sugerir, construir, elaborar, concluir, sentindo-se satisfeito com os resultados atingidos. No entanto, na maioria das vezes, a pesquisa escolar é vista como uma "tarefa a ser cumprida em tempo hábil" para avaliação do professor, onde os alunos desconhecem os procedimentos metodológicos e não recebem maiores orientações nem na sala de aula, através do professor e nem na biblioteca através do bibliotecário. Atualmente, percebese uma preocupação dos professores na realização da pesquisa escolar, para que a mesma oportunize a aprendizagem para os alunos, novos conhecimentos, a interação com o grupo, a realização pessoal através de um trabalho bem elaborado. Outra preocupação do professor é a orientação quanto ao uso das TIC's para que os objetivos sejam alcançados. Até a década passada, para a realização da pesquisa escolar, os alunos buscavam as informações diretamente no material impresso, através das fontes bibliográficas disponíveis na biblioteca ou nas fontes pessoais, através da oralidade utilizando instrumentos como entrevistas, relatos, entre outros. Hoje, as fontes se diversificaram e se multiplicaram, através da internet, considerada um facilitador inconteste do acesso à informação. No entanto, as dificuldades aumentaram, pois exigem dos alunos uma re-organização e o uso de estratégias de busca para que os mesmos tenham condições de elaborar um trabalho escolar de qualidade e que oportunize uma situação de construção de conhecimentos. É necessário também qualificar o professor para orientar, acompanhar pesquisas do início ao fim, avaliando todo o processo. Não apenas "solicitar o tema" e "receber a tarefa".

No processo da pesquisa escolar destacam-se dois atores principais : o professor e o aluno. Para completar o cenário, surge um novo personagem: o bibliotecário, com a função de orientar os dois primeiros na utilização adequada dos recursos das TIC's no processo da busca da informação e da aquisição do conhecimento através da pesquisa escolar.

\section{OS PERSONAGENS DO CENÁRIO: OS ALUNOS, OS PROFESSORES E OS BIBLIOTECÁRIOS}

“Conhecer é descobrir e construir e não copiar." (FREIRE,

A pesquisa escolar interessa aos educadores e aos alunos, tornando-se uma prática comum nas escolas, do Ensino Fundamental à Educação Superior, caracterizando-se como um trabalho de busca de informação e de conhecimento. Entende-se como informação a primeira condição para aquisição do conhecimento. Para a informação tornar-se conhecimento deve ser previamente processada pelo indivíduo, ou seja, interpretada para descobrir sua significação. "O processo de conhecimento é o de buscar soluções para determinados problemas."(AUTHIER, 2003). Para Castells (1999), "a informação, em seu sentido mais amplo, tem sido fundamental em todas as sociedades, [ . . . ] e o paradigma digital fez emergir a sociedade da informação e com ela a sociedade em rede. As ferramentas tecnológicas tornaram-se essenciais para a formalização e a disseminação do conhecimento." Segundo o autor, é preciso aliar à tecnologia a capacidade do indivíduo em aprender a captar, gerir, disseminar e aplicar o conhecimento adquirido. Sendo assim, a pesquisa escolar é uma das atividades que possibilita aos alunos a captação, a geração, a disseminação e a aplicação dos conhecimentos adquiridos. Para que isso ocorra, é necessário que as etapas de desenvolvimento sejam orientadas pelo professor e seguidas pelos alunos e 
bibliotecários, quanto à seleção do assunto, estratégias de busca e identificação das fontes, planejamento do trabalho, seleção e coleta de informações, organização das referências consultadas, organização dos registros para apresentação do trabalho (oral ou escrito). Uma das consequiências de não desenvolver as etapas de pesquisa escolar, é a cópia ou transcrição textual sem a identificação do autor, o que caracteriza o plágio. "Quando as fontes bibliográficas ao alcance dos alunos eram poucas - a biblioteca da escola ou da faculdade - , era fácil detectar o plágio. Com a Internet isso se tornou missão impossível". (SCLIAR, 2003, p.3). Quanto às fontes de pesquisa, estas objetivam o levantamento, a busca e o tratamento de informações que proporciona o embasamento do tema sugerido pelo professor.

A Sociedade da Informação preconiza a informação como um recurso prioritário e, o seu acesso, como um marco o qual insere os cidadãos na sociedade, auxiliando o exercício responsável e consciente na tomada de decisões em qualquer âmbito de ação e no exercício de seus direitos de cidadania. As TIC's facilitam a aquisição de conhecimento permitindo $\mathrm{o}$ acesso às fontes de informação, o cruzamento de informação de diferentes fontes e áreas, a comunicação em tempo real ou virtual com outras pessoas e a disponibilização de meios rápidos e eficientes de processamento da informação. Um dos fatores que os atores deste cenário devem levar em consideração é o papel que as TIC's exercem como mediadoras do processo de ensino e de aprendizagem, através do Ambiente de Aprendizagem Mediado por Computador AAMC, na estratégia educativa em que dois ou mais sujeitos constróem seu conhecimento através da discussão, da reflexão e da tomada de decisões. Os efeitos do uso da informação compartilhada entre os educadores, os bibliotecários, os alunos, pode encaminhar para uma rede integrada de comunicação, permitindo o estabelecimento de novas relações entre os mesmos (inter-relação de pessoas) e destes com a comunidade.

As evoluções das TIC's têm proporcionado ferramentas utilizadas como fontes de busca para a pesquisa, localizadas na biblioteca da escola. O panorama das bibliotecas escolares no Brasil, não difere muito da realidade de um Estado para outro: acervos desatualizados e em condições de precariedade, deficiência de mobiliário e equipamento, falta de recursos humanos qualificados, espaço físico insuficiente para acomodação dos usuários, entre outros. $\mathrm{O}$ material disponível para a realização da pesquisa escolar, tem como suporte, na grande maioria, o livro, pois a internet, quando existe na escola pública, tem prioridade nos laboratórios de informática ou na secretaria, preterindo a biblioteca e o atendimento aos seus usuários. Grande percentual do acervo bibliográfico é originado de doações e, muitos dos livros, são destinados ao professor, para análise para ser indicado ou não aos alunos. Além disso, a biblioteca escolar é considerada um apêndice da sala de aula, quando deveria ser uma extensão do processo de ensino e de aprendizagem vivenciada na mesma, "pulsando viva, como o coração da escola". Nesse panorama das bibliotecas escolares, o Rio Grande do Sul se diferencia dos demais Estados brasileiros, por manter o Sistema Estadual de Bibliotecas Escolares -SEBE previsto na Constituição Estadual (Artigo 218), que prevê dentre outros, uma política de recursos humanos qualificados para atuar nas mesmas. Vigora também a Lei Estadual $n^{\circ} 8884$ de 9 de novembro de 1988 que prevê, entre outros, recursos do Orçamento do Estado para atualização de acervo e aquisição de mobiliário e equipamento e a obrigatoriedade do horário de leitura em todas as séries de funcionamento do Ensino Fundamental. Apesar de todas as dificuldades das bibliotecas escolares a situação das bibliotecas de escolas gaúchas coloca o Estado em lugar de destaque, como se pode observar na Pesquisa divulgada pelo MEC sobre "O Retrato da Educação no Rio Grande do Sul" onde consta no item "Estrutura Escolar": Rio Grande 
do Sul lidera ranking das unidades da federação com mais alunos matriculados em escolas dotadas de biblioteca". (ZERO HORA, 2003, p.4).

\begin{tabular}{|c|c|c|c|c|}
\hline \multicolumn{3}{|c|}{ Ensino Fundamental } & \multicolumn{2}{|c|}{ Ensino Médio } \\
\hline 1 & Rio Grande do Sul & $-90,1 \%$ & $1^{\circ}$ Rio Grande do Sul & $98,6 \%$ \\
\hline 2 & Minas Gerais & $81,0 \%$ & $2^{\circ}$ Paraná & $97,4 \%$ \\
\hline 3 & Santa Catarina & $79,6 \%$ & $3^{\circ}$ Espírito Santo & $95,6 \%$ \\
\hline 4 & Paraná & $78,9 \%$ & $4^{\circ}$ Santa Catarina & $95,2 \%$ \\
\hline $5^{\circ}$ & Distrito Federal & $72,9 \%$ & $5^{\circ} \quad$ Minas Gerais & $94,7 \%$ \\
\hline Br: & & $55,6 \%$ & Brasil: & $84,3 \%$ \\
\hline
\end{tabular}

Quadro 1: Retrato da Educação no Rio Grande do Sul, com ano base em 2001.

No cenário das escolas embora um significativo número disponham das ferramentas tecnológicas para o ensino e a aprendizagem, preocupa ainda, a falta de uma "ação pedagógica digital", que propicie a articulação dos atores (alunos, professores e bibliotecários) na comunidade escolar, através do uso de informações que visam a construção de sua cidadania e integração social.

A experimentação do AAMC no processo da pesquisa escolar, os novos papéis que os alunos, educadores e bibliotecários assumem no processo de ensino e de aprendizagem, a busca correta das fontes, entre outros, contribuirão para a aplicação de metodologias do desenvolvimento da pesquisa escolar no Ensino Fundamental e Médio, na busca de informação e de conhecimento, otimizando o uso das TIC's existentes na escola, contribuindo para o benefício coletivo da comunidade escolar. A pesquisa escolar, vivenciada em cada sala de aula como procedimento racional e sistemático, proporcionando o envolvimento dos atores deste cenário, terá repercussões na formação superior e de pós-graduação e na qualidade da atuação profissional. Por isso a importância de compreender os novos papéis dos atores presentes no cenário da pesquisa escolar, suas atribuições e competências buscando novo enfoque para a proposição de um paradigma nas escolas, que envolva a Aprendizagem Colaborativa Mediada por Computador - CSCL (Computer Supported Collaborative Learning) como estratégia educativa onde as TIC's estão presentes como mediadoras do processo de ensino e de aprendizagem.

\section{A PESQUISA ESCOLAR E OS PRESSUPOSTOS TEÓRICOS}

E o que acontece quando temos ou enfrentamos um problema? Buscamos ajuda, pesquisamos dados, perguntamos, buscamos nossos amigos e colaboradores. Buscamos, enfim, o coletivo.(AUTHIER, 2003).

A presença das tecnologias no dia-a-dia da escola, propiciando a integração da Internet aos sistemas educacionais, torna-se mais um recurso e mais uma fonte de 
informação na promoção do ensino e da aprendizagem, evidenciando-se como um instrumento facilitador do processo educativo, na busca da informação. No desenvolvimento da pesquisa escolar o professor deve ser um facilitador e orientador para as buscas realizadas pelos alunos, em um ambiente construtivista. Por outro lado, os alunos devem se tornar o centro do processo de aprendizagem onde tenham o controle desse processo realizado em um ambiente cooperativo, autonomizador e interativo. Na concepção da teoria piagetiana, o conhecimento não está no sujeito, nem tampouco no objeto. O conhecimento é construído na interação do sujeito com objeto, por isso a interação sujeito-objeto é um ponto fundamental a ser considerado no projeto de ambientes de apoio à aprendizagem. Portanto, a interação é o requisito fundamental na epistemologia genética.

Neste novo paradigma, o aluno transforma-se de um agente passivo de recepção dos conhecimentos repassados pelo professor em um ser ativo, responsável pelo próprio desenvolvimento. O professor, por sua vez, perde seu posto de detentor e repassador de conhecimento a passa a ser aquele que fomente o desequilíbrio cognitivo do aluno (na busca de um reequilíbro em um nível cognitivo mais elevado). (NITZKE; FRANCO, 2002, p.24).

No ambiente construtivista, os alunos assumem a responsabilidade da sua própria aprendizagem, trazendo as suas estruturas e perspectivas às atividades desenvolvidas, reconhecendo que os indivíduos são "agentes ativos" que se comprometem com a construção do seu próprio conhecimento, integrando a nova informação no seu esquema mental e representando-a de uma maneira significativa. $\mathrm{O}$ aluno é o centro do processo de aprendizagem.

Franco (2003) afirma que “... quando paramos para refletir sobre o que acontece em uma sala de aula, descobrimos que temos mais perguntas que respostas. Por isso a atitude do professor comprometido é de estar em constante pesquisa." O autor também declara que o professor deve "estar em constante busca de compreender o que está ocorrendo. Isso significa investigar o porquê dos erros que os alunos cometem. Isso significa investigar porque determinado conteúdo parece tão fácil ou tão difícil."

Quando um(a) professor(a) se transforma em pesquisador(a), dá-se conta que conhecimento vem da pesquisa e bota os alunos a pesquisar. Ora, se o conhecimento não é uma simples aquisição de fora para dentro, mas uma construção (ou uma reconstrução) que o sujeito faz a partir de suas interações com o que o cerca, é conseqüência natural entender-se que o aluno precisa buscar ativamente o conhecimento. (FRANCO, 2003).

Vygotsky enfatiza que a inteligência humana provém da "nossa sociedade ou cultura" e que ocorre através da interação com o ambiente social, explicada através da teoria sociocultural, baseada na intersubjetividade e na zona de desenvolvimento proximal - ZDP. Para Vigotsky "o desenvolvimento cognitivo foi compreendido como uma conseqüência do conteúdo a ser apropriado e das relações que ocorrem ao longo do processo de educação e de ensino.”(FREITAS, 1995, p.101). Sendo assim, o aprendizado precede o desenvolvimento, quando a criança, através de sua experiência cotidiana, no convívio com as pessoas de seu meio, de sua cultura, forma e utiliza os 
conceitos espontâneos sem estar conscientes deles. No período de escolaridade, com a aquisição dos conceitos científicos, ela adquire a capacidade de defini-los por meio de palavras e de operar com os mesmos.

Poder-se-ia dizer que o desenvolvimento dos conceitos espontâneos da criança é ascendente, enquanto o desenvolvimento dos seus conceitos científicos é descendente, para um nível mais elementar e concreto. Isso decorre das diferentes formas pelas quais os dois tipos de conceitos surgem. (VYGOTSKY, 1987, p.93).

A pesquisa escolar contribui para propiciar que o conceito espontâneo abra caminho para o conceito científico e este forneça estrutura para o desenvolvimento daquele, tornando-os consciente e deliberado.

Andler (1998, p.56) afirma que a capacidade de aprender supõe a assimilação de novas informações, "sua estocagem e sua assimilação tendo em vista modificar as estruturas do conhecimento, as estratégias perceptivas e a ação." Esta aprendizagem supõe a comunicação. As informações devem circular entre as estruturas do conhecimento e os indivíduos. Segundo o autor, os aspectos que os conceitos de cognição recobrem, são a percepção, a ação finalizada, a organização conceitual, o raciocínio, a aprendizagem, a comunicação e a linguagem.

\section{CONSIDERAÇÕES FINAIS}

Às vezes quando se fala em transformar os alunos em pesquisadores, se entende como desincumbir o professor de seu compromisso de dar aulas. Ora, a construção do conhecimento só se dá nas trocas com os outros, e o saber diferenciado do professor torna-se elemento essencial nesta construção. Portanto, não deixemos de lado a necessária dialogicidade da relação professor-alunos. As trocas de idéias e os espaços de orientação que precisam ocorrer. (FRANCO, 1997).

Com o advento da sociedade da informação e com ela a sociedade em rede, as TIC's tornaram-se importante instrumento para a construção do conhecimento. A internet foi um elemento facilitador no processo de ensino e de aprendizagem, auxiliando as estratégias de busca de fontes para a pesquisa escolar, atividade cotidiana nas salas de aula do Ensino Fundamental e do Ensino Médio. O ensino informativo e enciclopédico está sendo substituído por um ensino mais formativo, com maior participação e interação dos alunos, professores e bibliotecários, que compartilham responsabilidade colaborativas e solidárias de investigação de temas que tenham como eixos norteadores a reconstrução dos seus conhecimentos.

Ao elaborar a atividade de pesquisa escolar, é importante que os alunos adquiriam a competência de realizar consultas em diferentes fontes (pessoais, bibliográficas, tecnológicas) que localizem os assuntos procurados independentemente, que identifiquem as idéias principais do texto e saibam compreendê-las e interpretá-las, que relacionem assuntos correlatos, que elaborem sínteses e conclusões a partir dos textos lidos e que referenciem as fontes consultadas. Além disso, o uso de citações no 
corpo do trabalho, identificando o(s) autor(es) das mesmas, em respeito aos direitos autorais, para não caracterizar o plágio.

O conceito de cidadania parte do pressuposto inicial de que o sujeito exerce efetivamente sua cidadania plena se tiver a capacidade de fazer as suas próprias escolhas. Isto significa afirmar que o cidadão pleno, na sociedade moderna, é aquele consciente e ativo dos seus direitos individuais e coletivos. Nesse processo, a informação é um elemento fundamental. Porém, para que o cidadão consiga gozar plenamente de sua cidadania passa pela mediação do espaço público, isto é, pela mediação das instituições, dentre elas a escola. É um processo de aprendizagem e de vivências que as crianças iniciam na escola, através de diversas atividades, dentre elas a pesquisa escolar e exercem a cidadania, quando adultos.

No cenário da educação, os alunos, educadores e bibliotecários devem exercer um papel ativo de atores principais e não de coadjuvantes, em um palco onde a colaboração, o compartilhamento e a cooperação estejam presentes em todos os atos da realização da pesquisa escolar, propiciando uma inter-relação de pessoas na busca de um novo paradigma na sociedade da informação, irradiando o benefício coletivo e o exercício da cidadania.

\section{REFERÊNCIAS}

ANDLER, D. (Org.) Introdução às Ciências Cognitivas. Trad. Maria Suzana Marc Amoretti. São Leopoldo: UNISINOS, 1998.

AUTHIER, M. A Construção Coletiva dos Conhecimentos. In: Revista I-Coletiva. NICE - Núcleo de Inteligência Coletiva Aplicada à Educação, n. 11, 27 fev. 2003. Disponível em: < http://www.icoletiva.com.br > Acesso em : 27 fev. 2003.

CASTELlS, M. A . A Sociedade em Rede. $2^{a}$. ed. São Paulo: Paz e Terra, 1999.

DEMO, P. Pesquisa Princípio Científico e Educativo. São Paulo: Cortez, 1990.

FARIA, E. V. de. Novas Possibilidades de Ensino de Língua Materna com o Apoio da Tecnologia. In: CONGRESSO DA SOCIEDADE BRASILEIRA DE COMPUTAÇÃO,22, 2002, Florianópolis. Anais ... Florianópolis : SBC, 2002. P.5564.

FRANCO, S. R. K. O Construtivismo e a Educação. 6 ${ }^{\text {a }}$ ed. Porto Alegre: Mediação, 1997.

Educação Através da Pesquisa. Disponível em:

$<$ http://www.pgie.ufrgs.br/alunos_espie/espie/franco//public_html/textos/educacaopesq uisa.htm > Acesso em: 20 jul.2003.

FREIRE, Paulo. Pedagogia da Autonomia : saberes necessários à prática educativa. 6 ${ }^{\text {a }}$ ed. São Paulo: Paz e Terra, 1997. 
FREITAS, M. T. de A. Vygotsky \& Bakhtin: psicologia da educação : um intertexto. $2^{\mathrm{a}}$. ed. São Paulo: Ática, 1995.

LÉVY, P. A Inteligência Coletiva: por uma antropologia de ciberespaço. Trad. de Luiz Paulo Rouanet. São Paulo: Loyola, 1998.

NITZKE, J.; FRANCO, S. R. K. Aprendizagem Cooperativa: Utopia ou Possibilidade? In: Revista Informática na Educação: Teoria \& Prática, Porto Alegre, v 5, n.2, p.23-30, nov. 2002.

PIAGET, J. Ensaio da Lógica Operatória. São Paulo: Ed. da USP, 1972.

SCLIAR, M. Plágio e Originalidade. Zero Hora, Porto Alegre, ano 39, n. 13695, p.3, 18 fev. 2003.

UNESCO. Biblioteca Escolar e Centro de Pesquisa: Esboço do Manifesto da Unesco. APB Circular, São Paulo, n.2, p.2-3, set.1998.

VYGOTSKY, L. S. Pensamento e Linguagem. São Paulo: Martins Fontes, 1987. 